\title{
Atmospheric Experimental Investigations of a Jet-Stabilized SOFC Off-Gas Combustor for a Hybrid Power Plant operated with Biogas
}

\author{
T. Lingstädt*, F. Grimm ${ }^{\dagger}$, T. Krummrein ${ }^{\ddagger}$, P. Kutne ${ }^{\S}$, M. Aigner ${ }^{\mathbb{I}}$ \\ Institute of Combustion Technology \\ German Aerospace Center (DLR) \\ Pfaffenwaldring 38-40, 70569 Stuttgart, Germany
}

\begin{abstract}
The increasing importance of decentralized energy production based on renewable resources requires gas turbine systems due to their low emissions and flexible energy conversion. Therefore, a suitable hybrid power plant demonstrator consisting of an SOFC (solid oxide fuel cell) coupled to an MGT (micro gas turbine) is being set up at the German Aerospace Center (DLR). This facility requires a burner concept for low calorific gases capable of combusting the exhaust products of the fuel cell system anode side, here referred to as SOFC off-gas. The combustor behavior for the demonstrator system is investigated using an atmospheric combustor test rig at DLR. The main aspect of this work is the combustor operation inside the power plant system with varying power demands and also varying methane contents, representing biogas operation. This is leading to operating points with very low heating values (LHV) which require a flame stabilization strategy via direct addition of natural gas / biogas into the SOFC off-gas before entering the combustor. This is tested in view of expected impacts on electrical system efficiency and other critical system parameters. The combustion system is furthermore investigated in view of $\mathrm{CO}$ emissions in various significant operating points.
\end{abstract}

\section{Nomenclature}

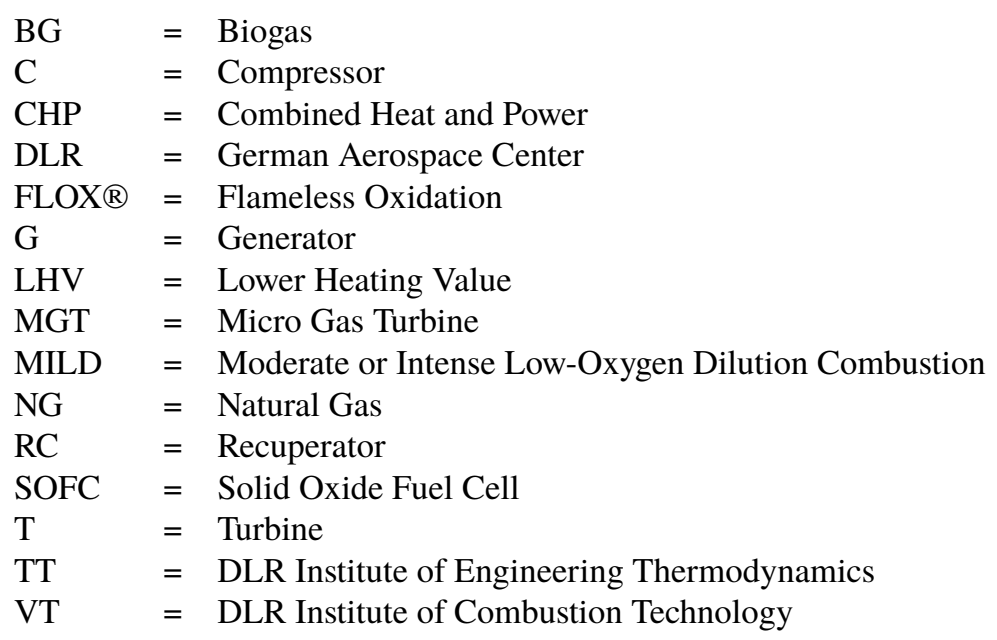

\footnotetext{
*Research Engineer, Institute of Combustion Technology, German Aerospace Center (DLR), Stuttgart, Germany, Timo.Lingstaedt@ DLR.de. ${ }^{\dagger}$ Research Engineer, Institute of Combustion Technology, German Aerospace Center (DLR), Stuttgart, Germany

* Research Engineer, Institute of Combustion Technology, German Aerospace Center (DLR), Stuttgart, Germany

$\S^{\S}$ Department Lead, Micro Gas Turbines, Institute of Combustion Technology, German Aerospace Center (DLR), Stuttgart, Germany

"Head of Institute, Institute of Combustion Technology, German Aerospace Center (DLR), Stuttgart, Germany
} 


\section{Introduction}

With fossil fuels being a limited energy source and at the same time high electrical energy needs, it is important to develop power plant concepts for decentralized power generation with high efficiency. One promising concept is the SOFC/MGT hybrid power plant, as currently being developed and built as a demonstrator at the German Aerospace Center (DLR) in a collaboration of the Institute of Combustion Technology (VT) and the Institute of Engineering Thermodynamics (TT) [1]. Hybrid power plants not only provide a large potential for efficiency increase but also for emissions reduction and operational flexibility. The presented work is based on a system, which integrates a solid oxide fuel cell emulator into a standard micro gas turbine cycle between compressor and turbine, as shown in Fig. 1 .

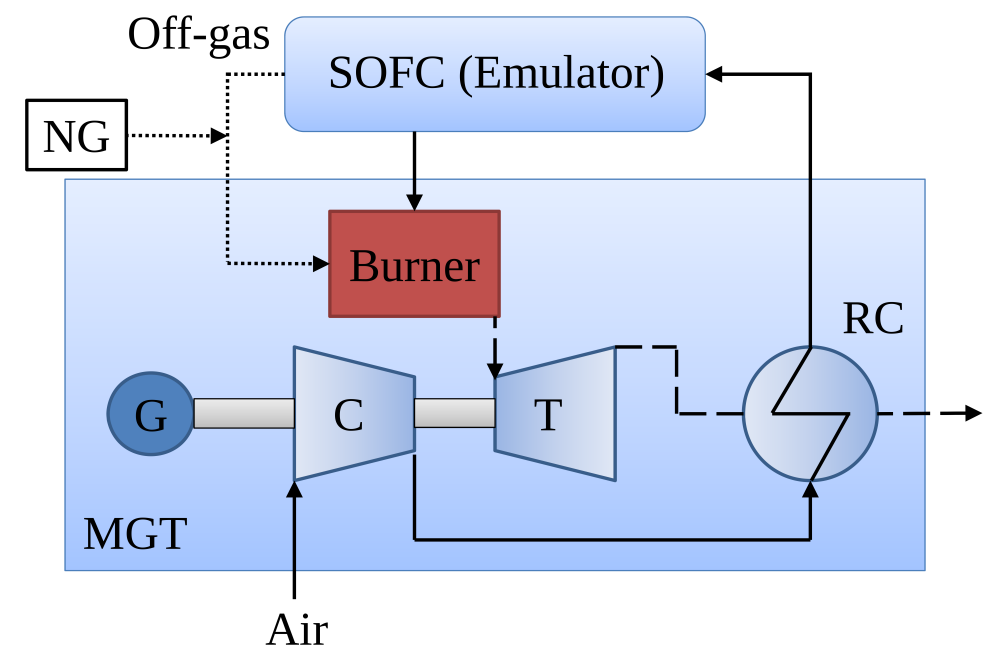

Fig. 1 Simplified Hybrid Power Plant Cycle with Off-Gas Emulation [2] with the Components G: Generator, C: Compressor, T: Turbine, RC: Recuperator.

The generator is mounted on the shaft conventionally and the original recuperator from the micro gas turbine system, providing the necessary operating temperatures for the SOFC, is located prior to the SOFC (Emulator). The anode-side exhaust from the fuel-cell (referred to as SOFC off-gas) is used as fuel in the combustion chamber, while the cathode-side exhaust is used as oxidizer. The off-gas typically consists of about $0.5-2 \% \mathrm{H}_{2}, 5-10 \% \mathrm{CO}$, about $40 \%$ $\mathrm{H}_{2} \mathrm{O}$ and $50 \% \mathrm{CO}_{2}$. This leads to an LHV in the range of $1-3 \mathrm{MJ} / \mathrm{kg}$, depending on the operating point and initial fuel. Since the fuel cell uses a significant amount of the contained oxygen, the oxidizer is characterized by a reduced $\mathrm{O}_{2}$-content compared to air of about $15-18 \%$. For the presented work, an atmospheric test rig is used in order to characterize the developed burner towards its final purpose of running in the power plant under the resulting low-caloric conditions. Those are provided as operational boundary conditions from the overall power plant specifications via numerical cycle simulations. The investigated burner is coupled with an SOFC emulator [3] in order to simulate the thermodynamic and fluid dynamic properties of an actual fuel cell. An additional natural gas / biogas supply is used for stability reasons in part load operation with low caloric off-gas. As mentioned previously, one of the key features of the power plant demonstrator is operational flexibility. Therefore, the developed burner has to provide a wide operational range, including SOFC off-gas and standard natural gas operation. As pointed out by Bücheler et al. [3], existing SOFC applications employ catalytic or conventional diffusion combustion systems [4], which are not particularly suited for attached turbine processes. In the present work, a partially premixed, jet-stabilized FLOX ${ }^{\circledR}$-similar combustor is used. The FLOX ${ }^{\circledR}$ concept was originally designed as volumetric or MILD combustion for the use in industrial furnaces [7, 8]. In the latest MGT combustion systems however, the jet-stabilized combustion features mainly discrete flames rather than volumetric combustion, which is only achieved under very lean part load conditions. Fuel is injected coaxially in the main flow direction in order to partially premix air and fuel in an upstream mixing section before entering the combustion chamber. Due to the high jet velocities, a strong inner recirculation zone is present, where hot combustion products are transported back to the reaction zone. The results are a relatively homogeneous temperature distribution, a wide and stable operating range and low emissions [9, 10]. Furthermore, the flame flashback risk is reduced due to the high jet velocities, even for fuel with large flame speeds such as hydrogen [11, 12]. As summarized by Bücheler et al. [3], such jet-flame based FLOX ${ }^{\circledR}$ systems were extended with swirl-stabilized pilot stage burners, in 
order to further extend the burner operating range [13,-15]. The combustor investigated in this work (see Fig. 2] is based on a twelve nozzle jet-stabilized concept [3] designed with regard to low total pressure loss while still providing high flexibility and stability.

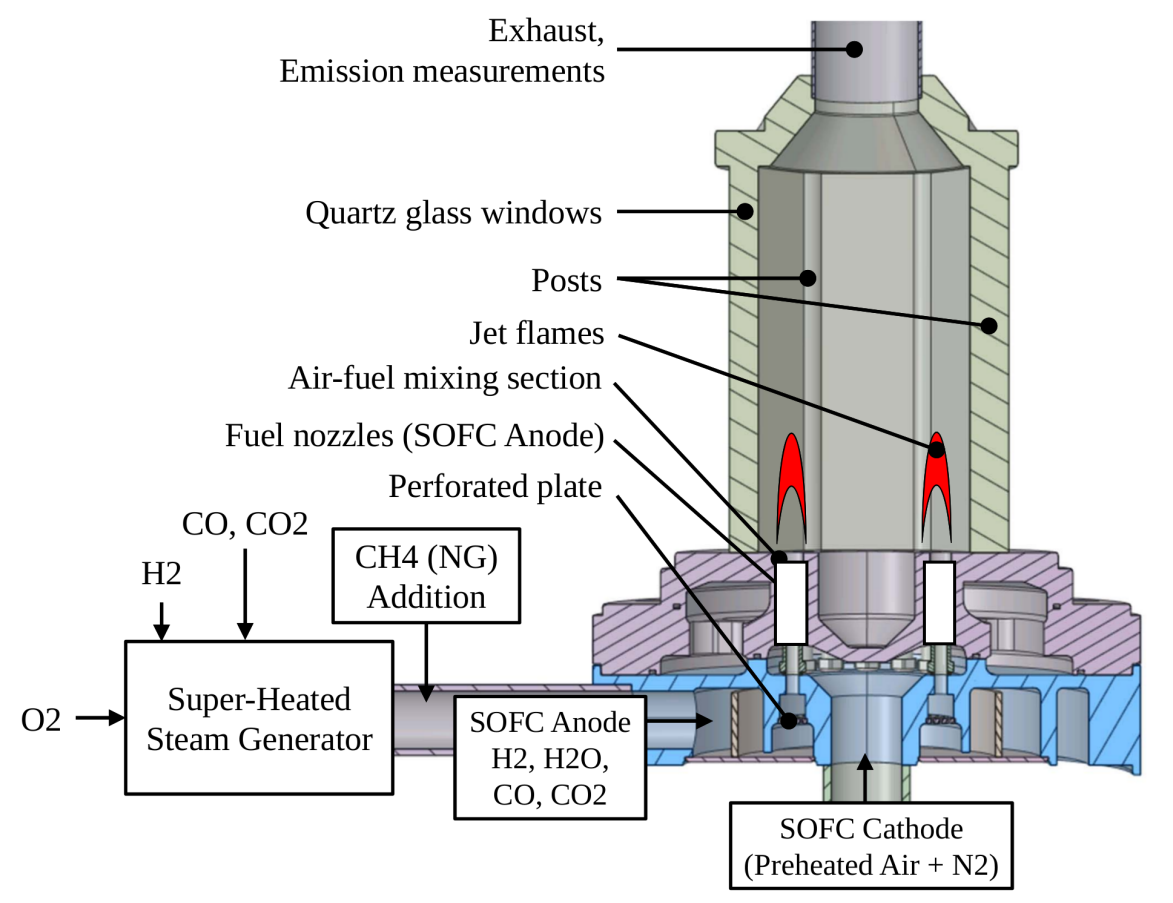

Fig. 2 Atmospheric Combustor Test Rig with Superheated Steam Generator [2].

The test rig consists of a controlled electric air heating device, providing the relatively high combustor inlet temperatures for the hybrid power plant application. Additionally the possibility to add $\mathrm{N}_{2}$ to the air is given, taking into account the reduced $\mathrm{O}_{2}$-content of the fuel cell cathode exhaust which has to be reproduced. The amount of $\mathrm{N}_{2}$ added to the air flow can be controlled via mass flow controllers, so that any required $\mathrm{O}_{2}$-content can be realized. A so called superheated steam generator, a device specifically developed to provide the required gas composition modeling the SOFC off-gas at a high temperature level, is connected as fuel supply to the test rig. This component is based on a hydrogen combustion chamber running under fuel-rich conditions equipped with the possibility to mix in the appropriate amounts of $\mathrm{CO}$ and $\mathrm{CO}_{2}$. The test rig is optically accessible. The integrated $\mathrm{OH}^{*}$-chemiluminescence signal and exhaust gas analysis are used for evaluation of the burner behavior.

With the elimination of a previously intended additional recuperator from the system design, the resulting operating conditions for the combustion chamber have changed significantly since the last investigations carried out in [3]. A remarkable decrease of the LHVs in the off-gas over the complete operational range of the power plant has demanded new investigations especially of the critical part load case and has led to new challenges guaranteeing a stable combustion over the whole operational range.

Especially for the planned biogas based operation of the described power plant setup, system cycle simulations show, that the operating conditions become even more difficult regarding the combustion process, since the resulting LHVs in the off-gas used as fuel are dropping even lower with the transition from natural gas as original fuel to different biogas mixtures. These issues are addressed in the presented work.

Regarding the future operation of the combustion system under pressurized conditions in the hybrid power plant test rig currently built at DLR, a very important aspect is the possible operating range of the hybrid power plant in terms of overall electrical system power output and electrical efficiency. Propositions towards the limitations of the combustion system and the resulting available operating range can be derived based on the presented results from the atmospheric combustor investigations. This topic will also be addressed. 


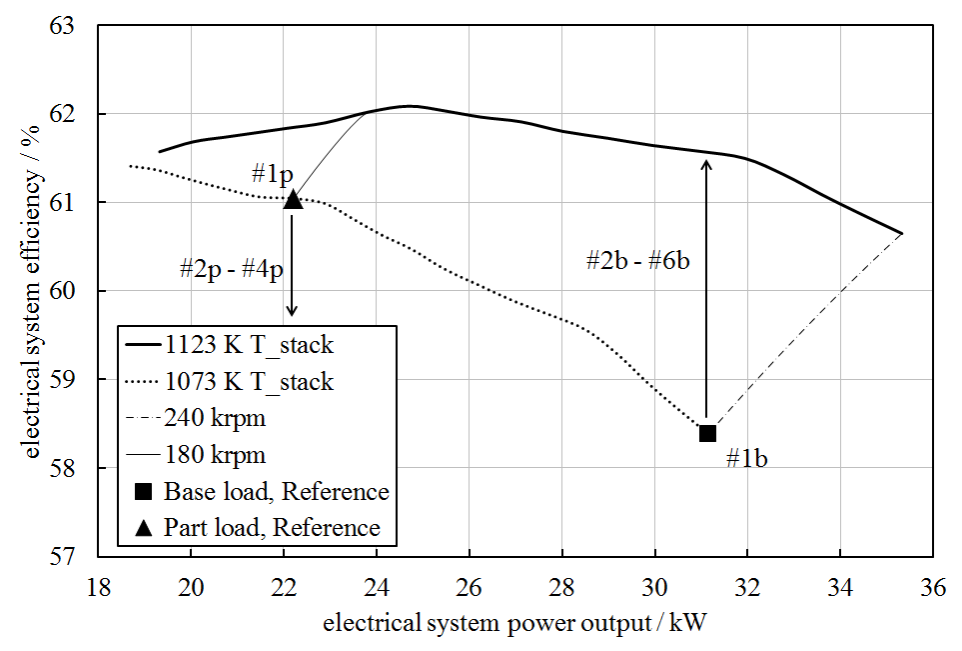

Fig. 3 System Efficiency over Electrical Power Output [2].

\section{Carried out Investigations and Present Results}

As described in [2], experiments on the atmospheric test rig on natural gas based off-gas operation have already been carried out at DLR. With these investigations it has been found, that the operation of the system, especially at low system power output, is quite challenging due to the low LHV and resulting low adiabatic flame temperatures. To ensure safe operation under these part load conditions, a direct addition of natural gas to the combustor has been found to be a successful method to stabilize the combustion. As illustrated in Fig. 3 (labeled \#2p-\#4p), this inevitably results in a decreased overall electrical system efficiency, since fuel is bypassing the SOFC. Hence, it is not fed to the system in the most efficient way. The electrical power output and efficiency data is based on stationary system simulations considering estimated heat losses. However, a significant reduction in $\mathrm{CO}$ emissions and flame stabilization could be achieved through the natural gas addition as shown in Fig. 4. The used representation of $\mathrm{CO}$ emissions over the air split is explained further in Sec. VI.C

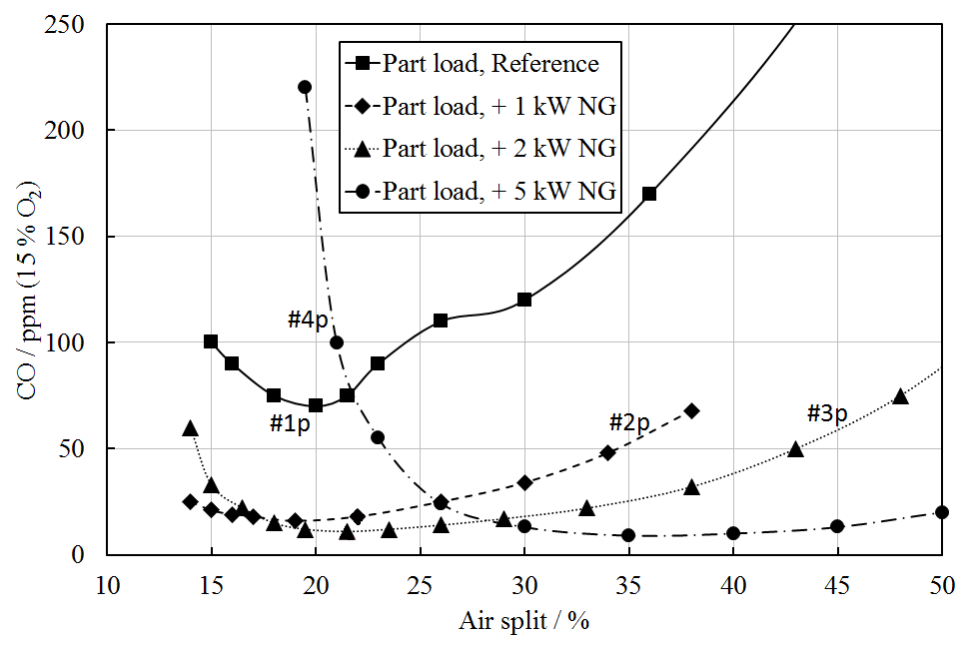

Fig. 4 Reduction of CO Emissions via Natural Gas Addition [2].

Additionally an optimization in terms of system efficiency through an increase of the fuel cell stack temperature could be achieved at the relatively stable base load operating point at maximum rotational speed of the MGT power module shaft. As shown in Fig. 5 a significant increase in fuel cell stack temperature was possible with sufficiently low corresponding increase in $\mathrm{CO}$ emissions. Hence, the operational range could be extended to more efficient operating points in terms of overall electrical system efficiency. 


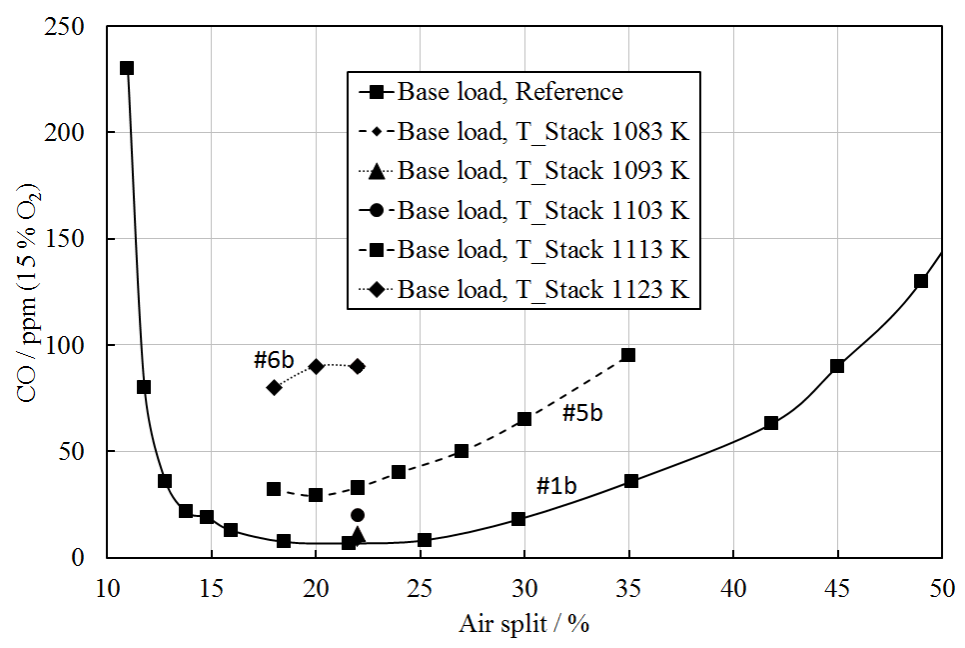

Fig. 5 Increase of Fuel Cell Stack Temperature [2].

\section{Atmospheric Test Rig Setup}

The examined SOFC-Offgas-Burner F20OG.01 is shown in Fig. 22 The vertically arranged combustion chamber of the atmospheric test rig from the nozzle plane upwards is optically accessible through quartz glass windows. As introduced before, the SOFC is not explicitly used for the atmospheric investigations, but is replaced by an upstream Superheated Steam Generator, representing essentially an $\mathrm{H}_{2} / \mathrm{O}_{2}$ combustor, that reproduces the necessary anode temperatures and gas compositions, as they would be emitted by the actual fuel cell. The described steam generator is designed explicitly to realize a large range of operating conditions, as given by the hybrid power operational range. It is divided into a combustion chamber with rich $\mathrm{H}_{2} / \mathrm{O}_{2}$ conditions to provide the demanded $\mathrm{H}_{2}$ and $\mathrm{H}_{2} \mathrm{O}$ content in the exhaust gas and a downstream mixing section, where $\mathrm{CO}$ and $\mathrm{CO}_{2}$ are injected as necessary. Natural gas can be added to the steam generator exhaust gas. This direct addition is done to provide stable combustion in case of part load conditions. This is challenging in this particular application due to very low resulting LHV and hence also very low adiabatic flame temperatures.

Next, the off-gas is redirected through a perforated plate, before it enters the combustion chamber through twelve annularly arranged fuel nozzles. Instead of pure air, a preheated mixture of air and nitrogen is used. This addition of $\mathrm{N}_{2}$ to the air is necessary to reproduce the demanded oxygen content, which is reduced compared to air depending on the operating point due to the electrochemical reaction in the fuel cell. The resulting mixture is distributed equally by an upstream plenum before it reaches the premixing zone around the twelve fuel nozzles in order to realize a partially premixed regime in co-flow alignment.

After a short premixing zone, the partially premixed gas issues into the combustion chamber, where discrete jet flames form the reaction zone. Combustion products then leave the combustion chamber through an exhaust duct, which also contains the temperature controlled probe for the exhaust gas measurements. Finally, the exhaust gases are directed outside the laboratory from above the test rig via an extraction fan.

\section{Measurement Techniques}

\section{A. Emission Measurements}

The exhaust gas to be analyzed is directed from the probe in the converging section downstream of the combustion chamber through temperature controlled feed hoses to an ABB process gas analyzer (Advanced Optima Process Gas Analyzer AO2000). The original chemical composition of the exhaust gases are preserved inside the temperature controlled probe and hosing. The gas analyzer is able to detect the combustion products $\mathrm{H}_{2} \mathrm{O}$ and $\mathrm{CO}_{2}$ as well as oxygen contents and pollutants. For this case, the focus for pollutant emissions lies on carbon monoxide (CO) as an indicator for a successful combustion process.

Since the LHVs and subsequently the adiabatic flame temperatures are very low over the range of all considered operating points in this work, NOx emissions are expected to be negligible. As no significant NOx emissions over 
$5 \mathrm{ppm}$ are detectable over the whole operating range, they are not regarded further.

$\mathrm{CO}$ emissions are shown on a dry basis and normalized to $15 \%$ oxygen. The data is sampled with a frequency of $2 \mathrm{~Hz}$ over a range of $2 \mathrm{~min}$. Information about the achievable accuracies of the emission measurement system can be found in [16].

\section{B. Optical OH*-Chemiluminescence Measurements}

Under atmospheric conditions, the electronically excited $\mathrm{OH}^{*}$ radical emerges mainly in the reaction zone. Therefore, it is a well suited indicator for the heat release zone. Sampled and averaged over time, it is used as an indicator of mean flame shape and to extract an approximation of the lift-off height. Its existence is very short and its decay can be described by the reactions [17][18], where Eq. 1] and Eq. 2] describe the radiation by transition to stable $\mathrm{OH}$ with $\mathrm{M}$ as collision partner.

$$
\begin{array}{rll}
\mathrm{OH}^{*} & \leftrightarrow \mathrm{OH}+\text { radiation } \\
\mathrm{OH}^{*}+\mathrm{M} & \leftrightarrow \mathrm{OH}+\mathrm{M}
\end{array}
$$

For the image detection, a CCD LaVision camera (Imager Pro Plus 2M) with a LaVision IRO image intensifier is used. The $\mathrm{OH}^{*}$-signal is detected with a lens resolving wavelength within $250 \mathrm{~nm}$ and $410 \mathrm{~nm}$. Multiple optical and transmission band-pass filters are applied to the camera system in order to block background noise and luminescence. The recorded and line-of-sight integrated volume and the measurement system positioning relative to the combustor are shown in Fig. 6. The presented $\mathrm{OH}^{*}$-chemiluminescence pictures are normalized to a fixed value, hence are quantitatively comparable to each other in terms of intensity.

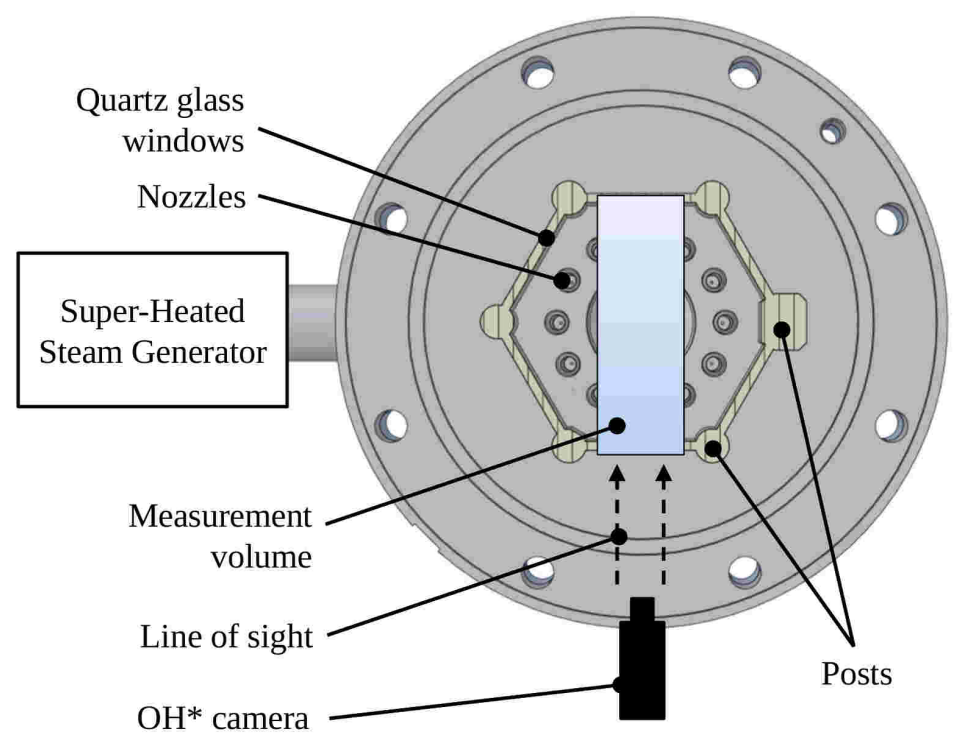

Fig. 6 Top View onto the Combustor with indicated OH* Measurement Volume and Camera Position [2].

The camera is positioned as such, that two flames are located in a row with the line-of-sight direction.

\section{Experimental Results}

\section{A. Detailed Investigations of Natural Gas Operation}

Since the carried out investigations in [2] with only two reference points are not sufficient to derive a suitable operational strategy for the complete operational range of the hybrid power plant, additional investigations on the atmospheric test rig at DLR are performed. To be able to refine the knowledge about the limitations, the combustion system is adding to the power plant, additional power levels, defined by the rotational speed of the power module shaft, 
are investigated. Five different levels of power output are considered sufficient for this purpose. They are defined by the rotational speed of the turbine shaft and set to the maximum allowable shaft speed of $240 \mathrm{krpm}$ (representing $100 \%$ relative power output), $221 \mathrm{krpm}(87 \%), 202 \mathrm{krpm}(75 \%)$ and $180 \mathrm{krpm}(61 \%)$ for the intermediate power output levels, as well as $164 \mathrm{krpm}(53 \%)$ for low power level. The listed relative power output levels significantly depend on other system parameters such as fuel cell stack temperature and gas composition and are only to be seen as rough references.

\section{Maximum Power Output}

For the maximum power operating point at the nominal maximum shaft speed of $240 \mathrm{krpm}$ a stack temperature variation has been carried out to evaluate the available margin for the operating range in terms of this highly impacting parameter of the fuel cell system. The fuel cell can be operated in a defined operating range in terms of temperature between $800^{\circ} \mathrm{C}$ and $850^{\circ} \mathrm{C}$. Due to system simulations it is known, that this parameter has an impact on the resulting operating conditions for the combustion chamber. Fig. 7 shows the significant decrease of the lower heating value with increasing fuel cell stack temperature. Although coupled to a slight increase in temperature at the combustor inlet, this results in overall lower adiabatic flame temperatures and less favorable operating conditions regarding emissions and flame stability. The empirically found critical area where no successful operation is possible on the atmospheric test rig is shaded gray.

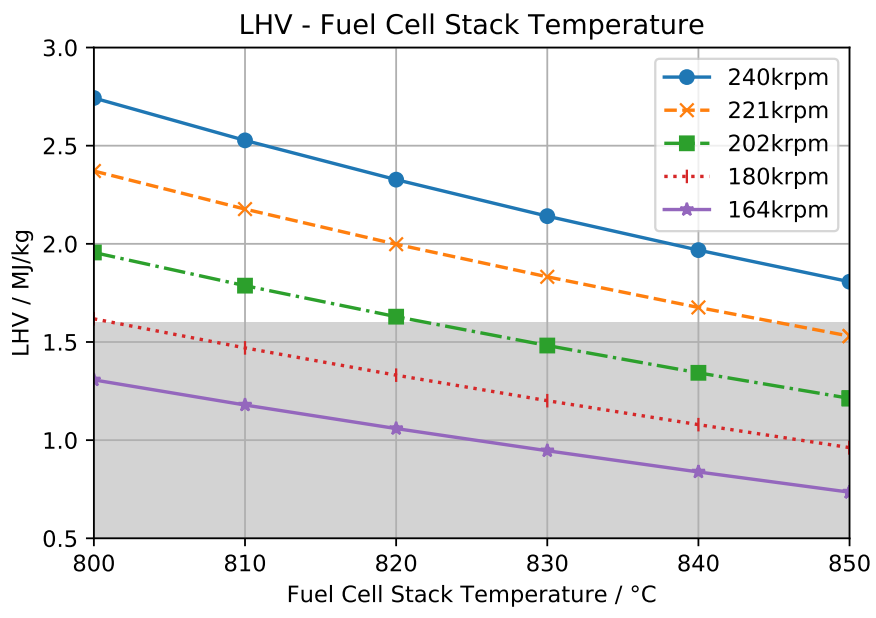

Fig. 7 Resulting LHV over Fuel Cell Stack Temperature for various Power Levels. No Operation possible on Atmospheric Test Rig in Shaded Area.

Air variations are carried out on the atmospheric test rig, based on discrete steps in fuel cell stack temperatures. The necessary information about the resulting gas composition is extracted from system simulations performed in house at DLR.

The results of these variations are shown in Fig. 8. The values depicted on the $\mathrm{CO}$ axis represent the corrected values based on a $15 \% \mathrm{O}_{2}$ content in the exhaust gas. By comparing the different curves, representing staggered fuel cell stack temperatures, it becomes clear that the combustor is working at a very low emission level through all investigated operating points. Around the individual optimum operation, the corrected emissions lie between 7 and $18 \mathrm{ppm}$, which can be considered very clean.

The behavior towards lean conditions and lower adiabatic flame temperatures is very consistent throughout the individual temperature curves and a rather accurate value of $1380 \mathrm{~K}$ can be considered as a universal low limitation representing the critical emissions value of $85 \mathrm{ppm}$ due to local regulations for gas turbine based combined heat and power (CHP) plants [19].

Nevertheless, a consistent increase in emissions is observed towards higher stack temperature values as expected due to the lower heating values of the resulting off-gas. It has to be noted that the adiabatic flame temperature does not represent a free to chose parameter in the power plant system and is depending on the choice of air split (representing the portion of process air fed directly to the combustor of the total amount of air including dilution). This important 


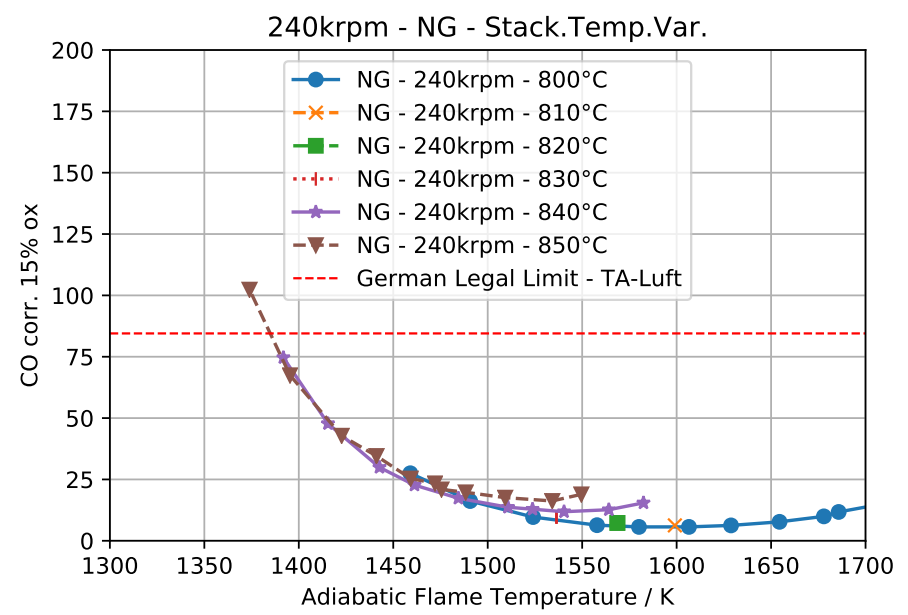

Fig. 8 Maximum Power Operation with Fuel Cell Stack Temperature Variation - CO-Emissions over Adiabatic Flame Temperature.

discussion of the actual realizable operating conditions in terms of adiabatic flame temperature in the power plant environment is addressed in Sec.VI.C.

\section{Intermediate Loads 221 and $202 \mathrm{krpm}$}

In addition to the carried out investigations in [2], two intermediate load levels located between the base load and part load level are added to the list of experiments. The results depicted in Fig. 9 show the changing behavior towards higher fuel cell stack temperatures. The combination of increasing stack temperatures with lower system power output levels compared to the previously described base load case result in higher $\mathrm{CO}$ emissions.
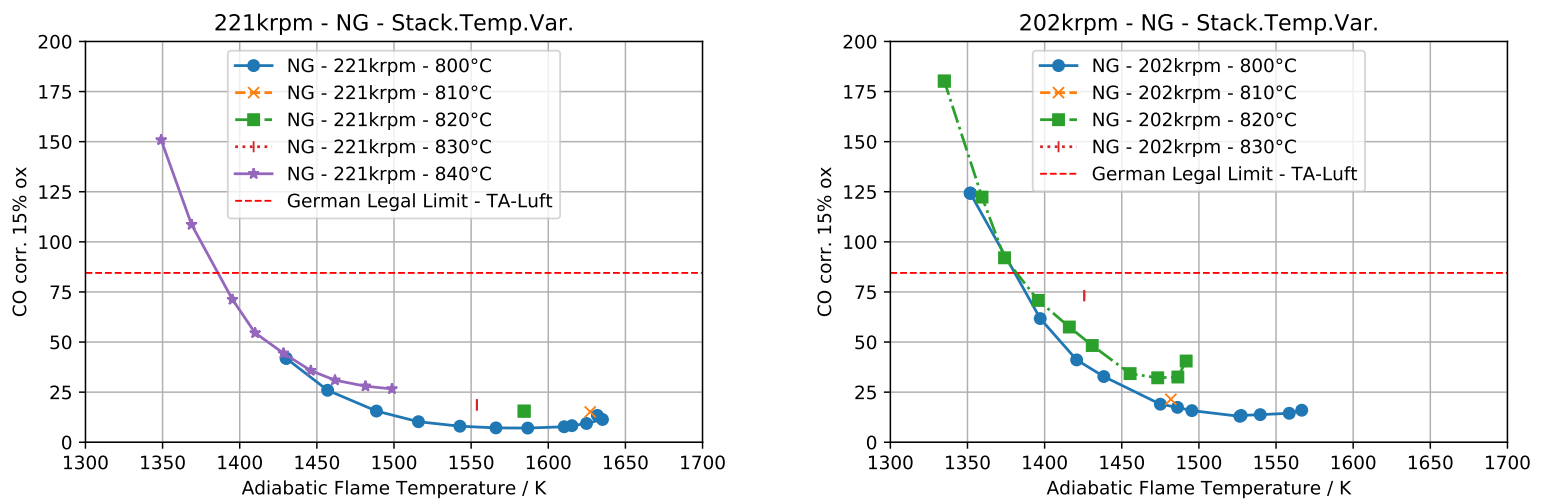

Fig. 9 Intermediate Power Operation with Fuel Cell Stack Temperature Variation - CO-Emissions over Adiabatic Flame Temperature.

For the first case at $221 \mathrm{krpm}$, a slight increase of the minimum possible emission value is evident but a wide range of low emissions and hence possible operating range for the system can be observed up to $840{ }^{\circ} \mathrm{C}$ stack temperature level.

With the step down to $202 \mathrm{krpm}$ this behavior changes significantly. The lowest possible emission levels are increasing further and with a stack temperature of $830^{\circ} \mathrm{C}$ the operating limit can be considered as exceeded, since even at the depicted optimum at this temperature level, $75 \mathrm{ppm}$ of $\mathrm{CO}$ emissions are reached.

As described later in Sec.VI.C, this information is used to define a possible operational range for the power plant system. 


\section{Part Load and Low Power 180 and $164 \mathrm{krpm}$}

With the transition to both of these considerably low rotational speed levels of the engine, an additional aspect has to be considered. A stable operation on fuel cell off-gas alone is not possible any more due to the inevitably exceeded lower limitation of adiabatic flame temperature. As a consequence, supplementary heat has to be added to the combustion chamber. This is achieved through the addition of small amounts of natural gas directly to the combustion chamber. The effect is a higher adiabatic flame temperature in the combustion chamber resulting in a more stable operation of the combustor. As this bypassing of the fuel cell, representing the most efficient component in the system, is shifting the energy flow in the system, it will always be connected to a decrease of overall electrical system efficiency. The impact of direct fuel addition on the system efficiency is further discussed in Sec.VI.C.

To investigate the effect on flame stability and burner operation, different levels of fuel addition represented by a corresponding heat flow, quantified in kW, are carried out and depicted in Fig. 10 .
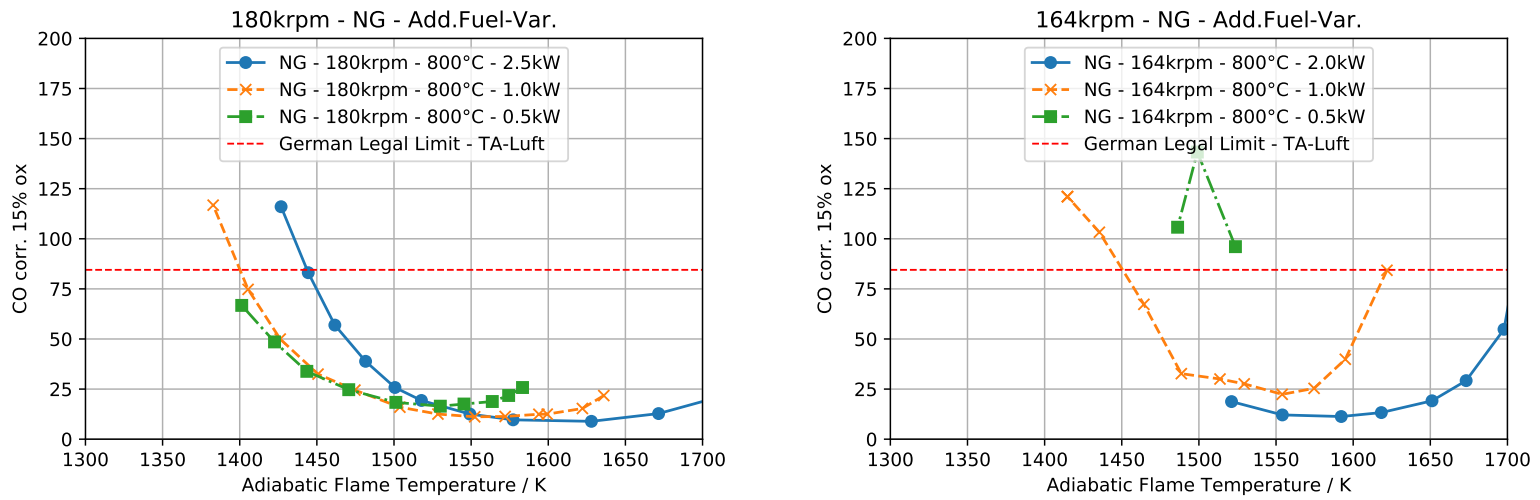

Fig. 10 Low Power Operation with Constant Fuel Cell Stack Temperature and Direct Fuel Addition to the Combustion Chamber - CO-Emissions over Adiabatic Flame Temperature.

For the $180 \mathrm{krpm}$ case it can be observed that already a very small amount of added natural gas $(0.5 \mathrm{~kW}$ represents about $3 \%$ of chemical system power input) leads to significant stabilization of the combustor operation and results in a wide operational range with relatively low emissions, compared to no flame at all without added natural gas. Although the $\mathrm{CO}$ emission can obviously be reduced further by increasing the additional heat, this should not be performed unless it is absolutely necessary to enable operation, since the impact on the system efficiency will always be negative. Additionally the combustion is shifted towards more fuel-rich conditions with a further increase, which is dragging the resulting operational range in terms of air split out of the designwise possible machine configuration at some point. This is leading to a situation where the matching for all operating points becomes impossible, as further explained in the system oriented consideration in Sec. VI.C.

With the lowest investigated power level at $164 \mathrm{krpm}$ the described effect becomes even more distinct. At the previously sufficient level of fuel addition of $0.5 \mathrm{~kW}$ no successful clean operation is achieved with $\mathrm{CO}$ emissions exceeding the national legal limitations in Germany of $85 \mathrm{ppm}$ dictated by [19] With a higher amount of direct fuel addition a satisfactory range with sufficient emissions is possible. Although the next step improves the combustion further, it has to be critically questioned if a match with the design restraints for the air split definition is still possible.

\section{B. Biogas Operation}

Regarding biogas operation, two representative operating points are investigated. For comparability reasons, the power levels already used in [2] at $240 \mathrm{krpm}$ and $180 \mathrm{krpm}$ are defined as reference base load and part load cases for this purpose.

The characteristic parameter for biogas specification used in the following section is the methane content. It represents the quality and contained heating value in the biogas mixture. For the investigations discrete steps from $100 \%$ methane content, representing previously discussed natural gas operation, down to $40 \%$ are defined to show the impact of biogas composition on the combustion system. Respective operating conditions for the combustor at $80 \%$, $60 \%$ and $40 \%$ methane content have been extracted from system simulations. To reproduce the required mixtures for the experiments, the necessary amount of inert media is added in form of $\mathrm{CO}_{2}$ to the natural gas supply depending on 
the desired gas composition.

\section{Base Load Operation}

The emission measurement results extracted from the base load cases for the different steps of methane content are shown in Fig. 11 .

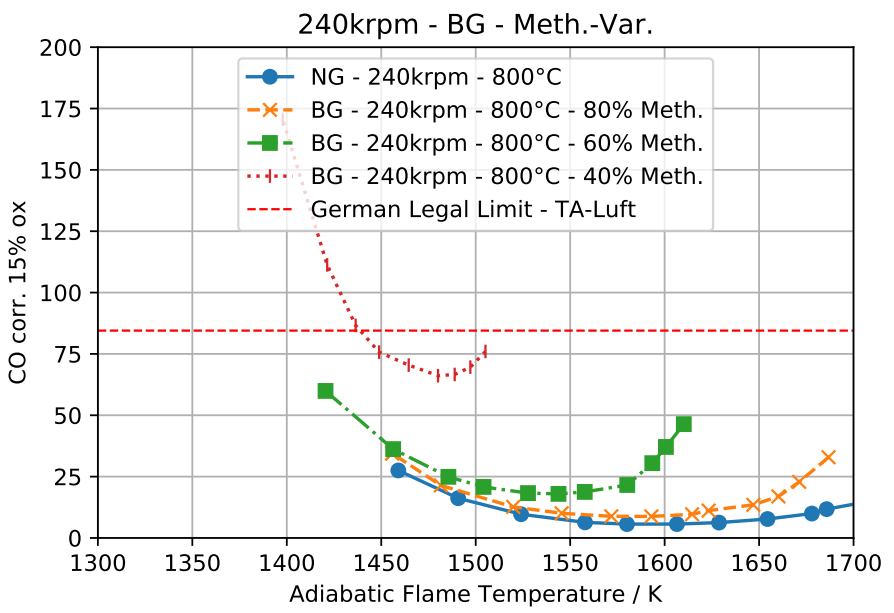

Fig. 11 Maximum Power Operation with Methane Content Variation - CO Emissions over Adiabatic Flame Temperature.

Regarding the $80 \%$ case, a very clean combustion is feasible over a wide range of air variation, nearly comparable to the natural gas case discussed before. With the $60 \%$ mixture, the operational range is getting more narrow and the achievable emissions optimum is settling at a higher level. This behavior is expected due to the lower resulting LHV with decreasing methane content. The correlation between the LHV and the methane content is depicted in Fig. 12 , again with the critical area shaded gray.

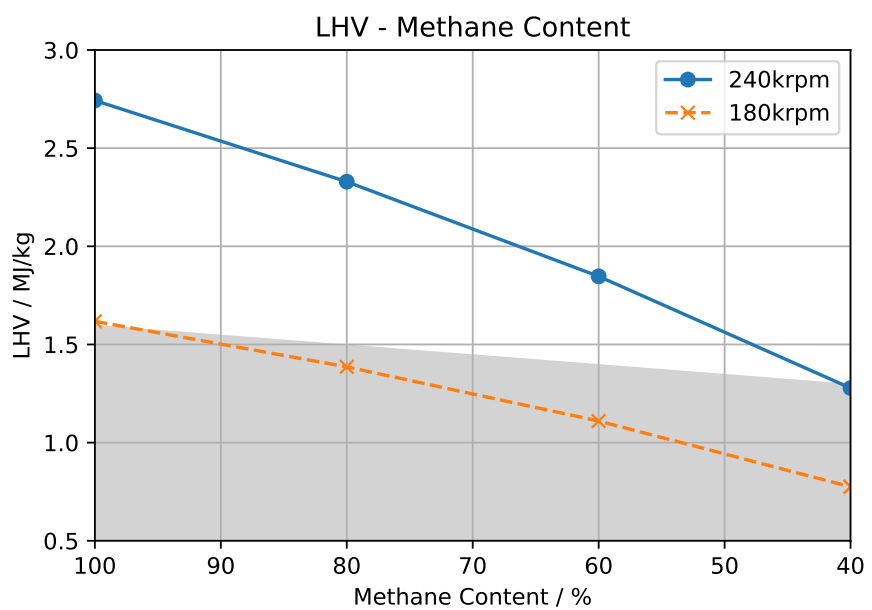

Fig. 12 Resulting LHV over Methane Content for both Reference Power Levels. No Operation possible on Atmospheric Test Rig in Shaded Area.

With $40 \%$ methane content, the impact becomes obvious and almost no operation with acceptable emissions is possible under the conservative conditions of the atmospheric test rig. The option of direct biogas addition to the combustion chamber in the base load case has not been investigated due to limited test rig capacity. Since the behavior 
near the stability limit of the combustor is highly influenced by heat losses, operation in the currently built turbine test rig will have to be awaited. In the closed, pressurized combustion chamber, accounting real heat flow conditions, it will be possible to safely evaluate, if the operation with the extremely low $40 \%$ biogas mixture is feasible.

The evolution of the flame shape with changing methane content can be observed in the corresponding $\mathrm{OH}^{*}$ chemiluminescence pictures in Fig. 13 .

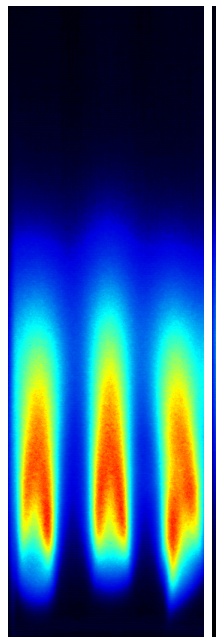

$100 \%$

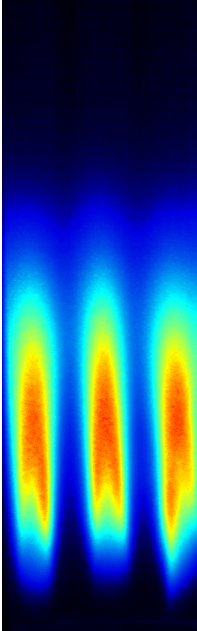

$80 \%$

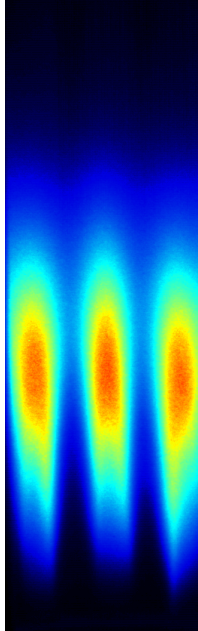

$60 \%$

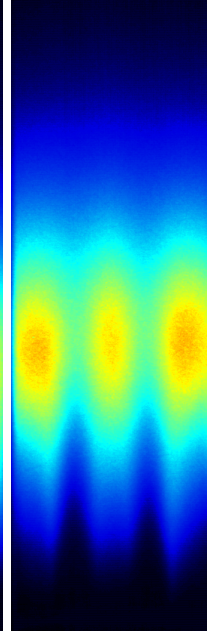

$40 \%$

Fig. $13 \mathrm{OH}^{*}$-Chemiluminescence - $240 \mathrm{krpm}$ - Varying Methane Content.

While the $80 \%$ case is still appearing rather similar to the corresponding natural gas case, a significant change in flame length, lift-off height and intensity can be noted towards lower methane contents. With this progression different changes in parameters affecting the conditions are connected. The higher $\mathrm{CO}_{2}$ content combined with similar heat input results in much higher mass flow in the gas supply. This leads to significantly increasing nozzle speeds with decreasing methane content. In combination with the overall lower adiabatic flame temperatures, which are dictated by the system simulations and hence the system design, this results in increased lift-off heights and decreased reaction intensity, represented by the $\mathrm{OH}^{*}$-levels. The increased nozzle speeds in combination with the reduced reactivity also explain the overall further pushed out location of the major heat release zone with decreasing methane content. As the higher nozzle speeds intensify the recirculation and with it the mixing of the components, the flame shape gets more volumetric and less discrete.

\section{Part Load Operation}

For part load operation under biogas conditions a direct fuel addition to the combustor bypassing the fuel cell has to be considered similarly to the natural gas case in Sec.VI.A As shown in Fig. 14, no acceptable operation is possible with both $80 \%$ and $60 \%$ mixtures without any fuel addition. Since the conditions become more challenging due to lower LHV and resulting lower adiabatic flame temperature, this behavior is expected with the knowledge from the natural gas case. In this case, of course the same biogas mixture from the corresponding base case is used for direct fuel addition. Consequently for biogas $80 \%$ the amount of direct added fuel is introduced in form of biogas $80 \%$.

The data shows, that the $80 \%$ biogas part load case can be operated stable within emissions limitations with a similarly low gas addition as for the natural gas case. The resulting operational range of the system is expected to be comparable.

For the $60 \%$ biogas case, a significant amount of fuel addition is necessary to allow for a stable operation. The resulting operating range is rather small and definitely approaching the limit of the combustor, at least in the atmospheric test rig. Again, since in this critical area the operation is highly affected by heat losses and the final combustion chamber design for the machine, only the results from the machine test rig will be able to show the precise boundaries for operation. A reduction in achievable power output range compared to the natural gas operation has definitely to be expected for a $60 \%$ biogas operation.

A stable operation for $40 \%$ biogas mixture was not possible in the atmospheric test rig for this part load case. It has to be expected, that a suitable operating line is not achievable for these conditions without changes in the system 

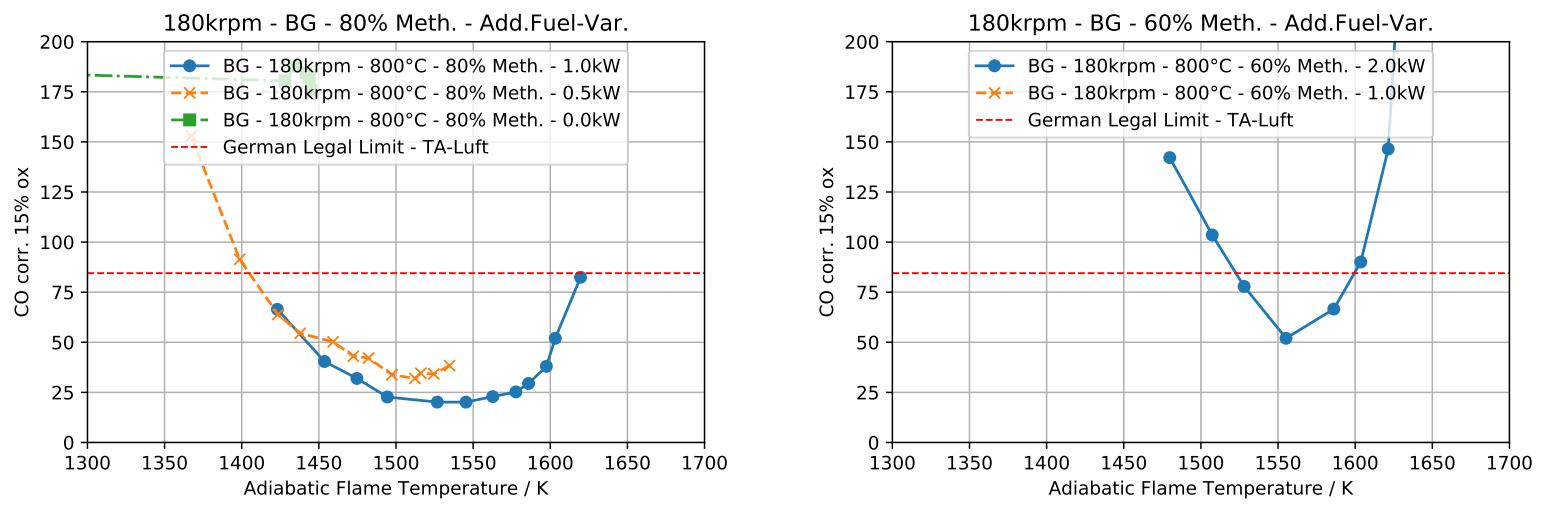

Fig. 14 Part Load Operation with $80 \%$ and $60 \%$ Methane Content and respective Direct Biogas Addition.

design, resulting in more favorable conditions for the combustor. However, it is possible, due to an expected significant reduction of heat losses in the final combustion chamber for the machine test rig, that a basic operation in a small power output range is achievable.

\section{System Operational Strategy}

As mentioned before, the chosen or at all possible operating conditions in terms of fuel cell stack temperature in high load operating points as well as the amount of directly added fuel to combustion chamber, highly affect the overall system performance in terms of electrical efficiency and possible flexibility, defined by the achievable absolute power output levels. Additionally, the definition of an air split configuration allowing for the best compromise between emissions, efficiency and power output range is a very important topic to be addressed.

As the previously used illustration of emission results, and hence operating range, in dependence on the adiabatic flame temperature does not have a direct correlation to the design of the combustion chamber, a new representation is introduced for the further results. The $\mathrm{CO}$ emissions for all power levels discussed in VI.A are represented over the air split in the appendix in Fig. 18 The air split is defined as the air mass flow fed to the combustion chamber through the nozzles divided by the total air mass flow including dilution air. Since this value is a fixed design parameter of the combustion chamber, it is possible to depict the different operating points towards one system configuration in one representation. This allows for the evaluation of their compatibility. In contrast to the previously used representation over the adiabatic flame temperature, now the fuel-lean area is located on the right side of the graph, characterized by high relative air-values.

In order to evaluate the influence on the complete system, another form of representation is used. In Fig. 15 the overall electrical system efficiency (electrical power output divided by the chemical energy input of the fuel) is depicted over the total electrical system power output as a representation of the power state. Hence, moving horizontally in the diagram represents a change of the power demand, while the vertical position describes the achieved efficiency. In this way of representation, the impact of the described variations of fuel cell stack temperature and direct fuel addition on the system becomes obvious.

Each data-set is representing a corresponding rotational speed. For the high power levels the positive influence of the stack temperature increase in terms of power output and efficiency can be observed. The hypothetical $800{ }^{\circ} \mathrm{C}$ operating line is depicted as well. With this as a reference, the achievable extension of the operating range in high load scenarios becomes obvious. The fact that the available margin is decreasing with lower rotational speed is illustrated quite good by the smaller available ranges in terms of stack temperature variation for $221 \mathrm{krpm}\left(800-840^{\circ} \mathrm{C}\right)$ and for $202 \mathrm{krpm}\left(800-820^{\circ} \mathrm{C}\right)$.

For the lower power levels, the impact of the direct fuel addition to the combustion chamber on the system can be seen. Starting from the $800^{\circ} \mathrm{C}$ reference line, the higher amount of direct fuel addition to the combustion chamber is not only coupled to a reduction in system power output, but also to a drop in system efficiency. 


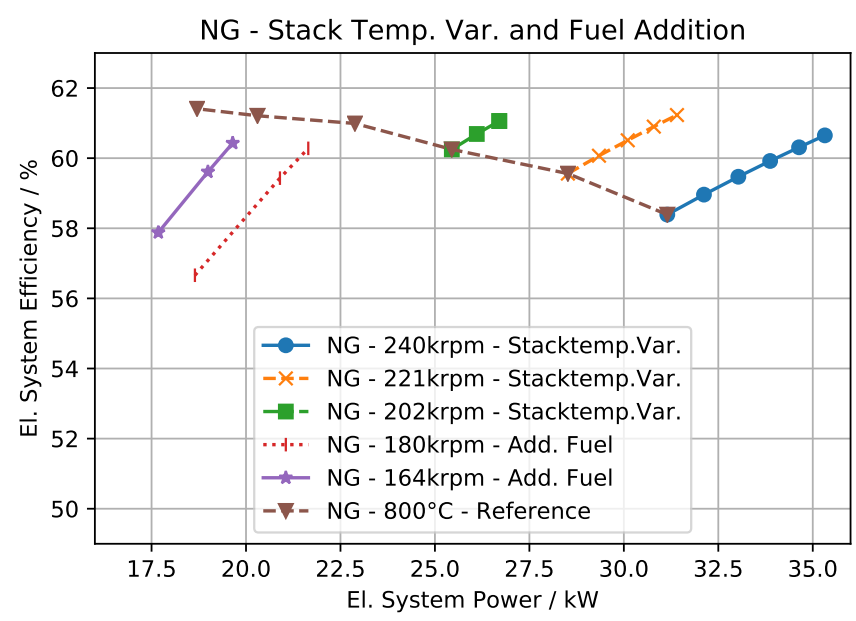

Fig. 15 Influence of Fuel Cell Stack Temperature and Direct Fuel Addition on Overall Electrical System Efficiency.

\section{Operation with Maximum Achievable Efficiency}

Based on the previously described information, a suggestion for the most efficient possible operational strategy for the power plant system, still fulfilling emissions requirements, can be made. In Fig. 16 the combination of the individual most efficient, but still feasible, operating points for each power level is illustrated as a possible Most Efficient Operating Line.

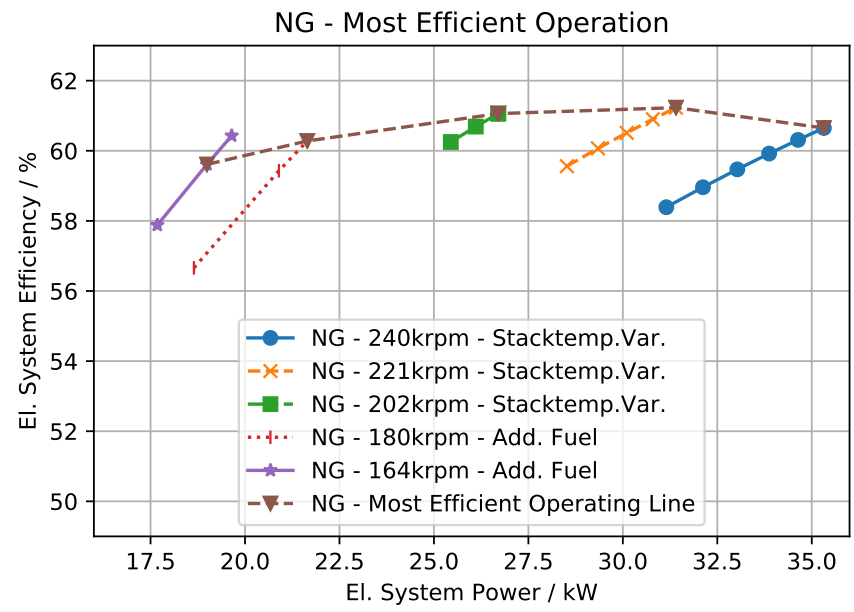

Fig. 16 Most Efficient Operating Line of Hybrid Power Plant System regarding Combustor Limitations.

A power range of at least $17.5 \mathrm{~kW}$ to $35.5 \mathrm{~kW}$ is achievable based on the atmospheric investigations of the combustion chamber. This represents a relative low power limit of about $50 \%$ of total system power output. Over nearly the complete achievable operational range the electrical efficiency is found to be at or above $60 \%$, based on the system simulations. Highest possible stack temperature levels and least necessary fuel addition in low power points are taken into account for this estimate.

In Sec.VI.A the necessary compatibility between the investigated theoretical operating points for different power levels of the combustor and the air split configuration of the machine combustion chamber (which has to be selected fixed) was mentioned. To be able to address and evaluate this topic, the emissions curves for all individual operating points of the Most Efficient Operating Line are depicted in the previously described way over the air split in Fig. 17

Since one value of air spit on the abscissa represents exactly one possible design configuration, the matching quality 


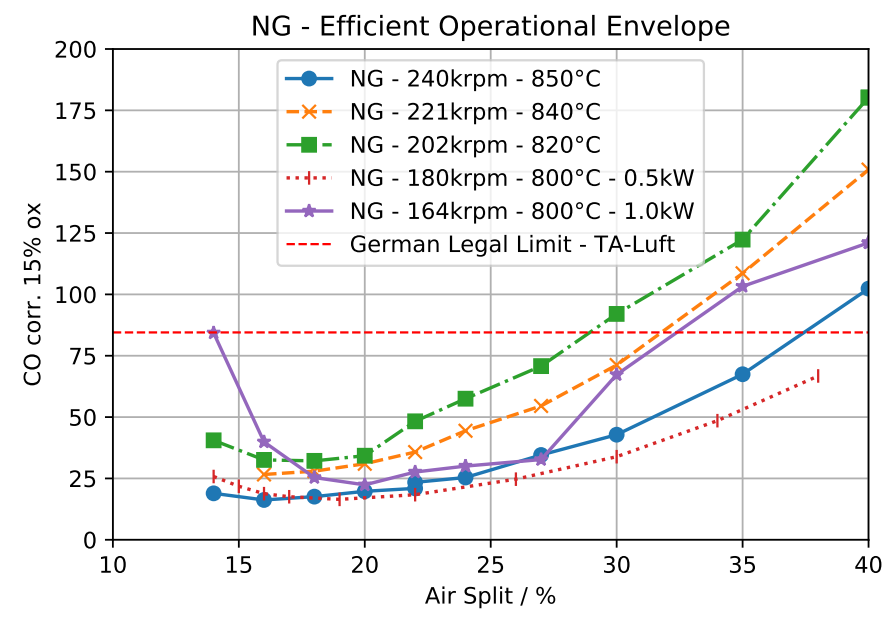

Fig. 17 Influence of Fuel Cell Stack Temperature on Overall Electrical System Efficiency

of the selected operating points can be evaluated. Ideally the minima of the individual emission curves for each operating point should meet at least close to one value of air split. This is given at or close below a value of $20 \%$ of air split for the illustrated case representing the Most Efficient Operation. Since the further addition of fuel at low power points is shifting the left rising branch of the curves towards higher air splits, the operational range in terms of absolute power output can be extended a little bit towards lower values by choosing a higher air split for the machine configuration. As the plot shows, this will inevitably be associated with higher emissions in high power scenarios. Depending on the requirements of the target system and the use case, the air split can act as a parameter to tune the system. Either towards low emissions in high power scenarios, sacrificing a little bit of low end power range, or towards wider range for the cost of higher emissions.

\section{Conclusion and Outlook}

Detailed investigations regarding natural gas operation were carried out. The results show a possible stable operation within emission limitations over a wide operating range of 50 - $100 \%$. In the high power regime the fuel cell stack temperature can add an additional degree of freedom inside the operational range of the system to a certain extent and can be used to tune efficiency and maximum power output. In the low power range a direct fuel addition is necessary to allow for a stable and clean combustion due to very low LHV and adiabatic flame temperatures dictated by the system design.

For biogas operation a reduction in methane content is possible with the current system design and combustor to about $80 \%$ without any noticeable impact on operational range or $\mathrm{CO}$ emissions. With a further reduction, the operational range in terms of system power output is expected to be restricted in the low power regime. The lowest considered methane content of $40 \%$ did not allow for a suitable operation in the current system design. However, the influence of the higher heat losses in the atmospheric test rig compared to the machine configuration are considered to be an important factor for the evaluation of the operating limits. These will be addressed more precisely in the gas turbine test rig, providing realistic heat flow conditions.

The minimum achievable operational range of the power plant operated with natural gas was specified based on the data from the atmospheric test rig. A most efficient operating line inside the possible operational envelope was suggested. Based on this operating line a power output range of about $50-100 \%$ of the maximum system power output is achievable with electrical efficiencies between mostly 60.0 and $61.5 \%$. A good match of the different power levels with a fixed air split configuration could be achieved, hence the operation along the suggested operating line is possible close to the individual corresponding emission optima.

For further investigations the combustion chamber will be implemented into the gas turbine test rig at DLR. In contrast to the atmospheric test rig, this allows for realistic heat flow conditions, which is expected to have a significant positive impact on the observed limitations towards low power operation. Especially the significant heat losses in the atmospheric test rig are expected to reduce the burner temperatures much more than in the closed and insulated 
combustion chamber for the gas turbine test rig. It could be observed that a marginal increase in preheating temperature of $10^{\circ} \mathrm{C}$, simulating a slightly lower heat loss, in the atmospheric test rig could be sufficient to make the difference between operation possible or impossible. This leads to the assumption, that the results from the atmospheric investigations are conservative in this specific case of already low adiabatic flame temperatures. In the gas turbine test rig the precise operating limits can be found and quantified for both natural gas and biogas operation.

Additionally it is planned to carry out CFD studies to account for possibly achievable improvements in the combustor design specifically regarding the extension of the biogas operational range.

\section{Acknowledgments}

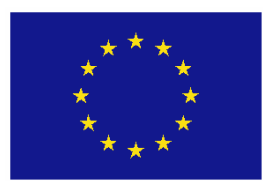

This project has received funding from the European Union's Horizon 2020 research and innovation programme under grant agreement No 641073 (www.bio-hypp.eu).

\section{References}

[1] Hohloch, M., Huber, A., and Aigner, M., "Analysis of Operational Strategies of a SOFC/MGT Hybrid Power Plant," Proceedings of the ASME Turbo Expo, Charlotte, NC, USA, 2017. GT2017-65013.

[2] Lingstädt, T., Grimm, F., Krummrein, T., Bücheler, S., and Aigner, M., "Experimental Investigation of a SOFC Off-Gas Combustor for Hybrid Power Plant Usage with Low Heating Values Realised by Natural Gas Addition," Proceedings of the GPPS Forum 2018, Global Power and Propulsion Society, Montreal, Canada, 2018. GPPS-2018-0052.

[3] Bücheler, S., Huber, A., and Aigner, M., "Development of a Jet-Stabilized Combustion System for the use of Low-Caloric SOFC Off-Gas," Proceedings of the ASME Turbo Expo, Charlotte, NC, USA, 2017. GT2017-64447.

[4] Hermann, F., Palsson, J., and Mauss, F., “Combustor Design Analysis for SOFC Off-gases,” 5th Solid Oxide Fuel Cell Forum, Lucerne, Switzerland, 2002.

[5] Loukou, A., Voss, S., Mendes, M., Raimondi, A., and Trimis, D., "Parametric experimental investigation of a small scale packed bed reactor for Thermal Partial Oxidation," 4th European Combustion Meeting, Vienna, Austria, 2009.

[6] Voss, S., Mendes, M., Pereira, J., and Trimis, D., "Comparison of Experimental and Numerical Results of Ultra-Lean H2/CO Combustion within Inert Porous Media," 4th European Combustion Meeting, Vienna, Austria, 2009.

[7] Wünning, J., and Wünning, J., "Flameless oxidation to reduce thermal NO-formation," Progress in Energy and Combustion Science, Vol. 23, No. 1, 1997, pp. 81-94. doi:10.1016/S0360-1285(97)00006-3.

[8] Cavaliere, A., and Joannon, M., "Mild Combustion," Progress in Energy and Combustion Science, Vol. 30, No. 4, 2004 , pp. 329-366. doi:10.1016/j.pecs.2004.02.003.

[9] Flamme, M., "Low NOx Combustion Technologies for High Temperature Applications," Energy conversion management, Vol. 42, 2001, pp. 1919-1935. doi:10.1016/S0196-8904(01)00051-6.

[10] Lückerath, R., Meier, W., and Aigner, M., "FLOX® Combustion at High Pressure With Different Fuel Compositions," Journal of Engineering for Gas Turbines and Power, Vol. 130, No. 1, 2008. doi:10.1115/1.2749280.

[11] Flamme, M., "New combustion systems for gas turbines (NGT)," Applied Thermal Engineering, Vol. 24, 2004 , pp. 1551-1559. doi:10.1016/j.applthermaleng.2003.10.024.

[12] Lammel, O., Stöhr, M., Kutne, P., Dem, C., Meier, W., and Aigner, M., "Experimental Analysis of Confined Jet Flames by Laser Measurement Techniques," Proceedings of the ASME Turbo Expo, Vancouver, Canada, 2011. GT2011-45111.

[13] Rödiger, T., Lammel, O., Aigner, M., Beck, C., and Krebs, W., "Part-Load Operation of a Piloted FLOX® Combustion System," Journal of Engineering for Gas Turbines and Power, Vol. 135, No. 3, 2013, pp. 031503-01. doi:10.1115/1.4007754.

[14] Zanger, J., Monz, T., and Aigner, M., "Experimental Investigation of the Influence of Combustor Cooling on the Characteristics of a FLOX®-Based Micro Gas Turbine Combustor,” Progress in Gas Turbine Performance, 2013, pp. 165-184. doi:10.5772/54405.

[15] Monz, T., Stöhr, M., O’Loughlin, W., Zanger, J., Hohloch, M., and Aigner, M., "Experimental characterization of a swirl stabilized MGT combustor,” Proceedings of the ASME Turbo Expo, Montreal, Canada, 2015. GT2015-42387. 
[16] Hasemann, S., Huber, A., Naumann, C., and Aigner, M., "Investigation of a FLOX@based Combustor for a Micro Gas Turbine with Exhaust Gas Recirculation," Proceedings of the ASME Turbo Expo, Charlotte, NC, USA, 2017. GT2017-64396.

[17] Dandy, D., and Vosen, S., "Numerical and Experimental Studies of Hydroxyl Radical Chemiluminescence in Methane-Air Flames," Combustion Science and Technology 19, 1992. doi:10.1080/00102209208951816, 131-150.

[18] Lee, J., and Santavicca, D., "Experimental Diagnostics for the Study of Combustion Instabilities in Lean Premixed Combustor," Journal of Propulsion and Power 19, 2003. doi:10.2514/2.6191, 735-750.

[19] Government of the Federal Republic of Germany, “Technische Anleitung zur Reinhaltung der Luft,”, 2002. 


\section{Appendix}
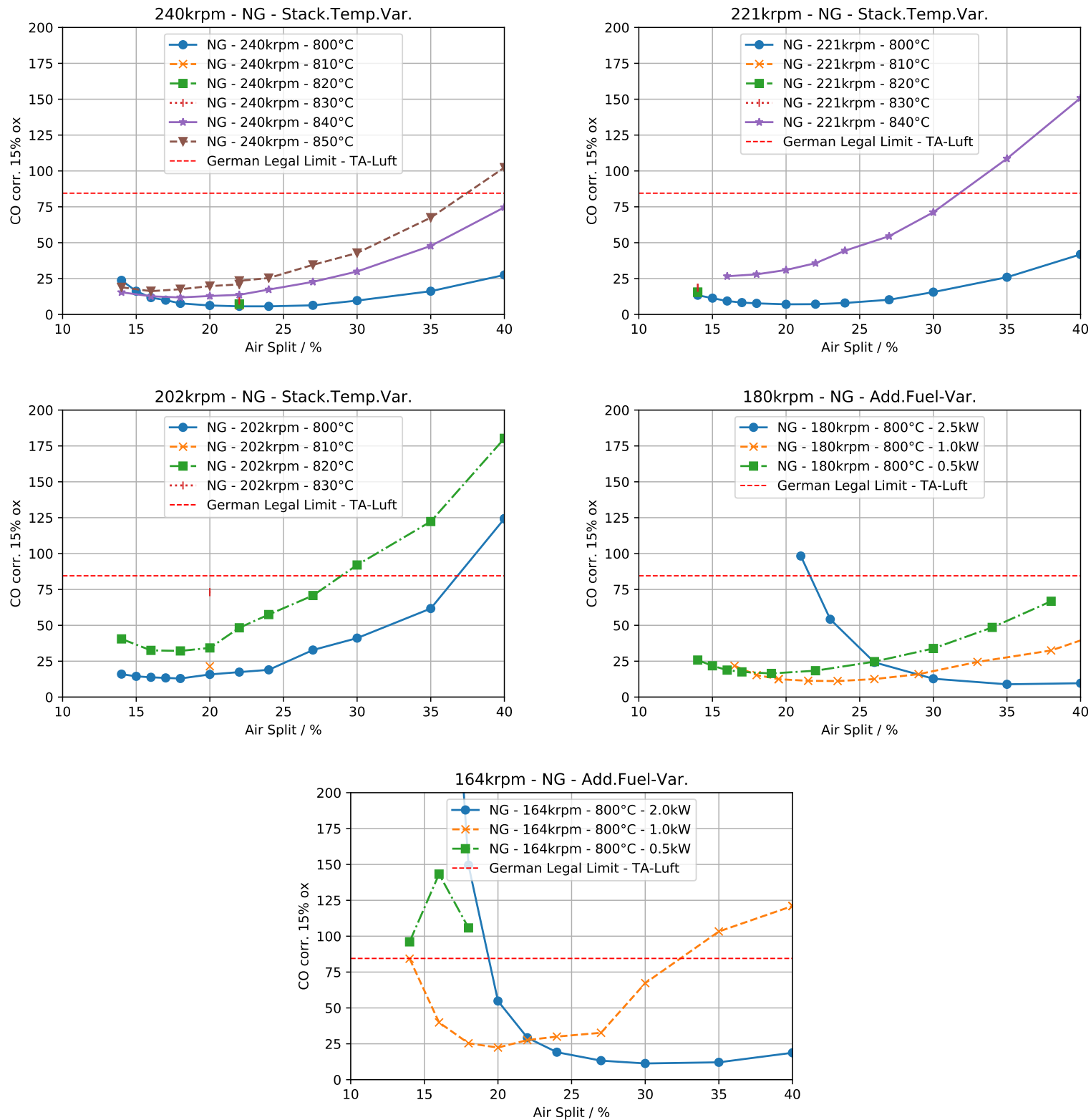

Fig. 18 CO-Emissions over Air Split - Natural Gas Operation. 